\title{
ON THE PERMANENCE OF RECOVERY IN ACUTE GLOMERULONEPHRITIS
}

\author{
By EMILY NICHOLS LOEB, JOHN D. LYTTLE, DAVID SEEGAL, \\ AND ELIZABETH L. JOST \\ (From the Department of Medicine and the Babies Hospital, College of Physicians and Sur- \\ geons, Columbia University, and the Research Division for Chronic Diseases, \\ Department of Hospitals, New York City)
}

(Received for publication April 28, 1938)

Although there is common agreement and occasional mention of the fact that nephritis once healed does not recur, there has been little evidence presented in the literature to substantiate this impression. Longcope (1) reports 4 cases out of a series of 24 with healed acute nephritis in whom beta hemolytic streptococci were found subsequently. Two of these, in a single throat culture each, revealed beta hemolytic streptococci, and, in a third patient, beta hemolytic streptococci were cultured repeatedly from chronically infected tonsils. Active invasion of tissue by the streptococcus, as measured by the antistreptolysin titer, was not reported. The fourth patient suffered a severe bronchitis caused by the beta hemolytic streptococcus. In none of these patients was there evidence of an exacerbation or recurrence of nephritis. Boyle et al. (2) mention the cases of 2 boys, each of whom they state had two distinct attacks of nephritis, each followed by complete recovery. Detailed data on the courses and urinary findings in these 2 patients were not given.

In the present study, a group of patients was observed during an attack of acute glomerulonephritis, after recovery, and during a subsequent infection. The infection at the onset of the acute glomerulonephritis and the subsequent infection were proved bacteriologically and immunologically to be caused by the hemolytic streptococcus. It was hoped that such a study might throw light on the alleged permanence of recovery in this disease. The present paper offers bacteriological, immunological, and clinical data on two groups of patients.

The case histories have been divided into 2 groups which are described in the following protocols and are presented in Tables I and II respectively. The 8 cases of Group I include all those observed over an approximately four-year period, from 1933 to 1937 . The two individuals in Group
II are selected on the basis of their unique manifestations.

\section{GROUP I}

\section{Case 1. C. B. (Hospital Number 80805)}

A girl of 5 was admitted with otitis media, recurrent mastoiditis, a postauricular abscess and acute nephritis. Blood pressure was $135 / 85$ and nonprotein nitrogen 34 mgm. per $100 \mathrm{cc}$. There was no edema. The urine showed albumin ++++ , many red blood cells, and casts. Hemolytic streptococci were cultured from the postauricular abscess and the antistreptolysin titer reached 833 units 3 days after onset of the nephritis.

Course. The urine cleared gradually and, in 6 weeks, showed albumin ++ and no red blood cells. In $2 \frac{1}{2}$ months, the urine was completely normal and remained so throughout the next 9 months, during which time 5 urine examinations revealed normal findings. The antistreptolysin titer declined progressively, reaching 250 units at the time of the first normal urine. Nine months from the date of the healing of her nephritis, the patient was readmitted with bilateral otitis media and pharyngitis. Hemolytic streptococci were cultured from the mastoid. Three weeks after admission, the patient developed erysipelas of the right cheek, and hemolytic streptococci were cultured from a bleb in this area. The antistreptolysin titer rose to 1250 units. The urine on admission showed minimal amounts of albumin and a normal sediment over a 6-weeks' febrile period. There were no clinical features suggestive of nephritis. The urine was found to be normal on 8 occasions in the next five months.

\section{Case 2. R. B. (Hospital Number 257472)}

A boy of 4 was admitted with a history of cervical adenitis and bilateral otitis media occurring 2 weeks before the onset of acute glomerulonephritis with gross hematuria. Blood pressure $116 / 70$. There was no edema. Blood nonprotein nitrogen was $63 \mathrm{mgm}$. per $100 \mathrm{cc}$. The urine, in addition to gross hematuria, showed albumin ++++ and casts. Hemolytic streptococci were cultured from the throat and the antistreptolysin titer reached 333 units 1 month after the onset of nephritis.

Course. The urine cleared progressively, showing albumin + and many red blood cells and casts at the end of a month. It was completely normal in 3 months and remained so over a period of 17 months during 
E. N. LOEB, J. D. LYTTLE, D. SEEgAL AND E. L. JOST

\begin{tabular}{|c|c|c|c|c|c|c|c|c|}
\hline & 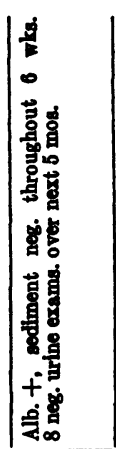 & 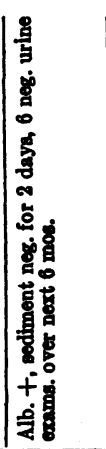 & 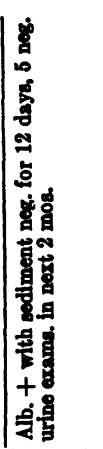 & 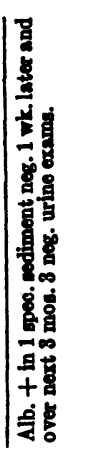 & 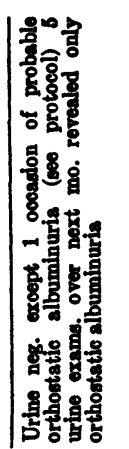 & 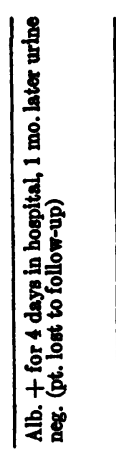 & 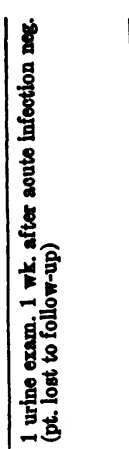 & 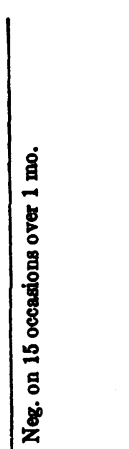 \\
\hline 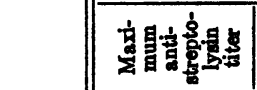 & 尊兽 & 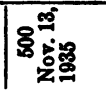 & 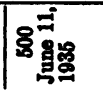 & 造 & 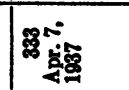 & 的 & 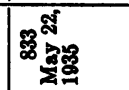 & 路 \\
\hline 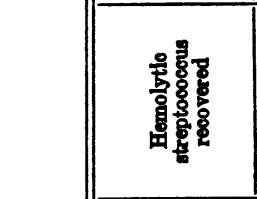 & 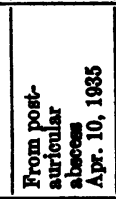 & 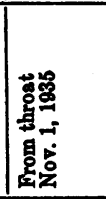 & 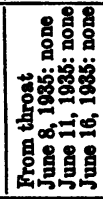 & 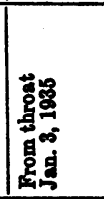 & 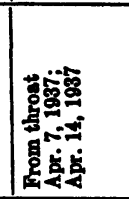 & 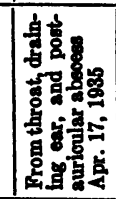 & 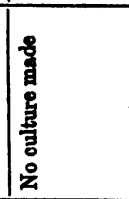 & 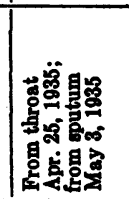 \\
\hline 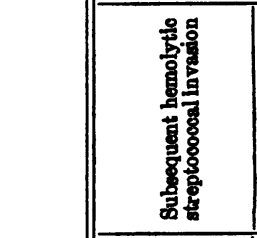 & 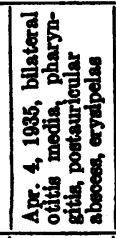 & 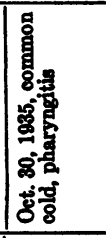 & 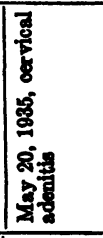 & 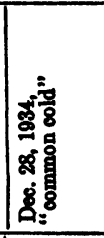 & 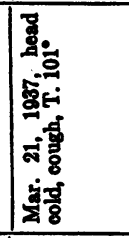 & 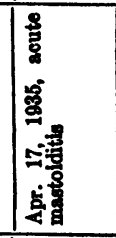 & 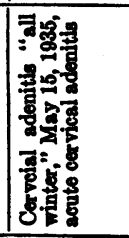 & 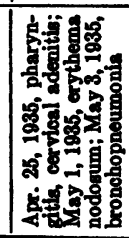 \\
\hline 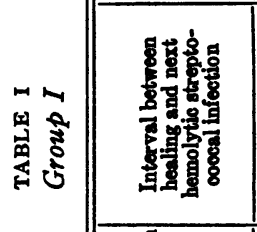 & 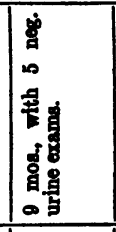 & 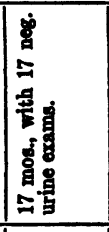 & 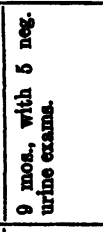 & 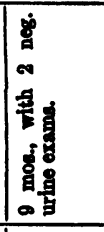 & 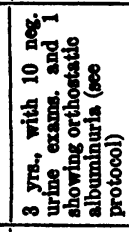 & 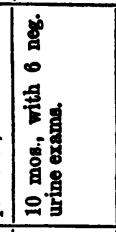 & 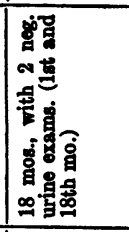 & 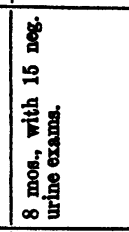 \\
\hline & | & \begin{tabular}{|l} 
音 \\
\end{tabular} & : & 音 & | & | & 亶 & 兽 \\
\hline 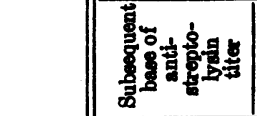 & F & 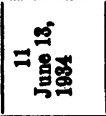 & 竞 & \$ & 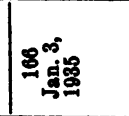 & हลं & 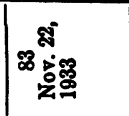 & के \\
\hline हूँ & 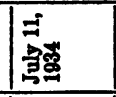 & | & 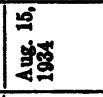 & 苾 & 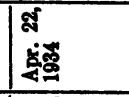 & 点 & 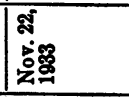 & 至哥 \\
\hline 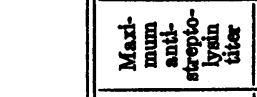 & 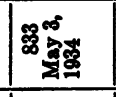 & 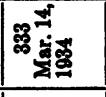 & 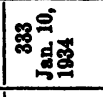 & 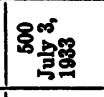 & 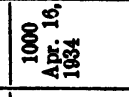 & 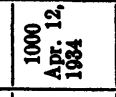 & 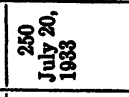 & | \\
\hline 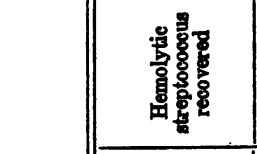 & 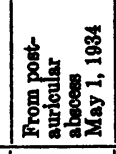 & 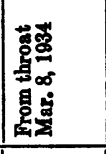 & 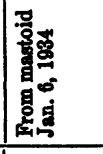 & 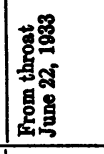 & 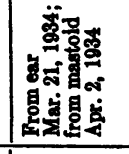 & 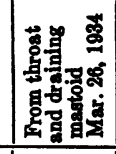 & 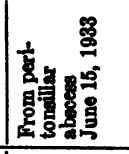 & 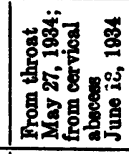 \\
\hline 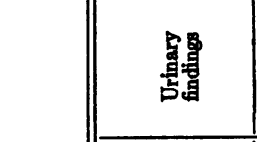 & 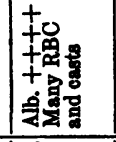 & 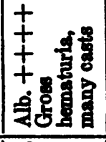 & 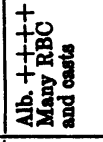 & 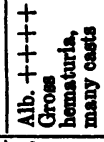 & 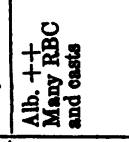 & 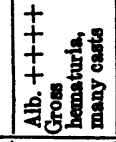 & 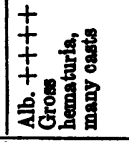 & 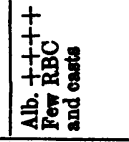 \\
\hline 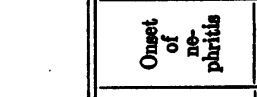 & 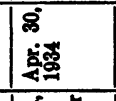 & 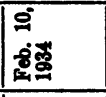 & |ت & 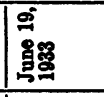 & 寞总 & | & 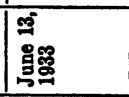 & 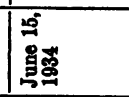 \\
\hline 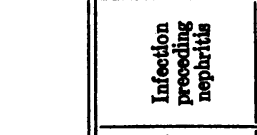 & 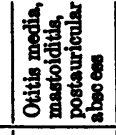 & 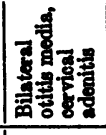 & 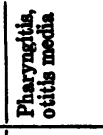 & 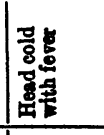 & 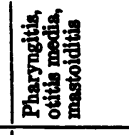 & 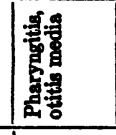 & 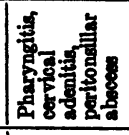 & 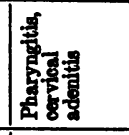 \\
\hline 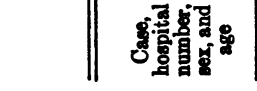 & 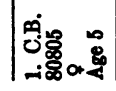 & $\mid$ & | & 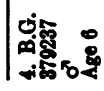 & 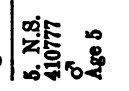 & 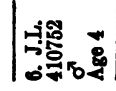 & 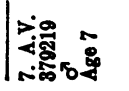 & 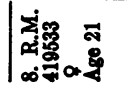 \\
\hline
\end{tabular}




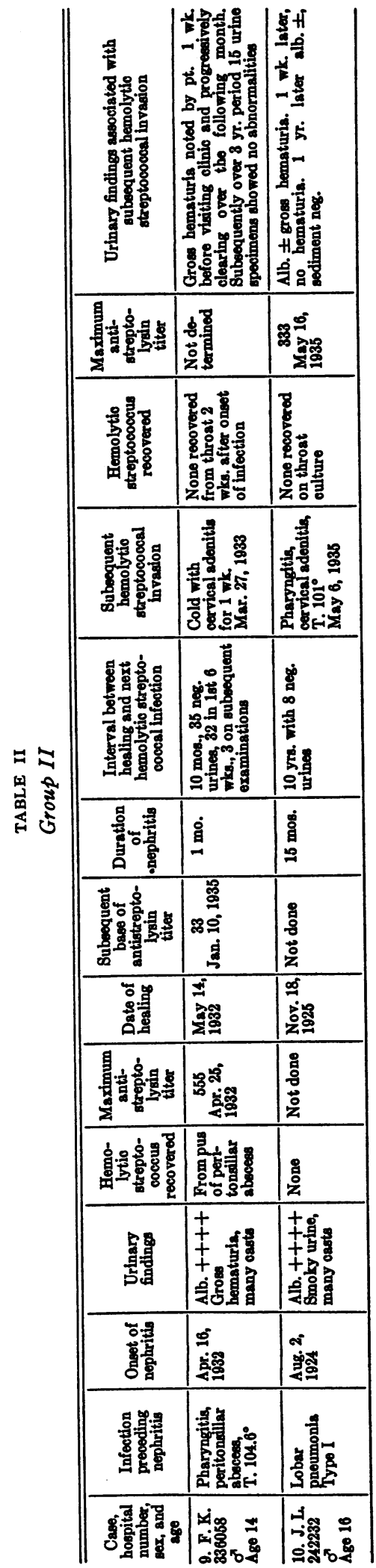

which time urine specimens revealing normal findings were observed on 17 occasions. The antistreptolysin titer had declined to 50 at the time of examination of the first normal urine. Seventeen months after the healing of his nephritis, the boy was readmitted with a head cold and pharyngitis. Hemolytic streptococci were cultured from the throat, and the antistreptolysin titer reached 500 units. The urine showed minimal amounts of albumin and a normal sediment over the 2 days during which fever was present. There were no clinical signs of nephritis. The urine then became negative and remained so over a 6-month period of observation in the clinic, during which time there were monthly urine examinations.

\section{Case 3. T. B. (Hospital Number 403728)}

A boy of 6 with a month's preceding history of pharyngitis and otitis media, was admitted with acute nephritis. There was no edema or hypertension. Blood nonprotein nitrogen was $39 \mathrm{mgm}$. per' $100 \mathrm{cc}$. The urine showed albumin ++++ , many red blood cells, and casts. Hemolytic streptococci were cultured from the mastoid at operation, and the antistreptolysin titer reached 333 units.

Course. The urine cleared progressively, showing only albumin ++ and 1 to 2 red blood cells at the end of 2 weeks, which minor findings persisted until they completely disappeared at the end of 7 months. At this time, the antistreptolysin titer had declined to 16 units. During the next 9 months there were 5 urine examinations all revealing normal findings. At the end of this time, the patient was readmitted with a history of cervical adenitis for 9 days, fever having reached $104^{\circ} \mathrm{F}$. Throat cultures on 3 occasions failed to show hemolytic streptococci, but the antistreptolysin titer was $\mathbf{5 0 0}$ units. The urine showed minimal amounts of albumin over a 12-day febrile period. There were no clinical features of nephritis. Five urine examinations over the next 2 months were normal.

\section{Case 4. B. G. (Hospital Number 379237)}

A boy of 6 with a history of head cold and fever for 2 weeks was admitted with acute nephritis, gross hematuria having been noted 3 days before admission. There was no edema, blood pressure was $104 / 60$, and blood nonprotein nitrogen was $59 \mathrm{mgm}$. per $100 \mathrm{cc}$. The urine showed albumin ++++ and casts in addition to the gross hematuria. Hemolytic streptococci were cultured from the throat. The antistreptolysin titer reached 500 units.

Course. The urine improved progressively, showing albumin ++ and 3 to 4 red blood cells per high power field at the end of 6 weeks when he was discharged. After 2 months, he was readmitted with an otitis media, his urine still showing albumin + and 1 to 3 red blood cells per high power field. The otitis media subsided in a week and the urine cleared progressively, becoming normal 9 months from his first admission. During the following 9 months, a urine examination upon 2 occa- 
sions revealed normal findings and the antistreptolysin titer was 111 units. At this time, the boy was seen in the clinic with a cold. Temperature was $103^{\circ} \mathrm{F}$. Hemolytic streptococci were cultured from the throat and the antistreptolysin titer reached 830 units. There was no clinical evidence of nephritis. The urine showed minimal amounts of albumin and a negative sediment on admission. One week later, and on 3 occasions over the next 3 months, the urine was negative.

\section{Case 5. N. S. (Hospital Number 410777)}

A boy of 5 with a 2 weeks' preceding history of pharyngitis and otitis media was admitted with acute mastoiditis and acute nephritis. There was no edema, blood nonprotein nitrogen was $31 \mathrm{mgm}$. per $100 \mathrm{cc}$, and blood pressure was $118 / 65$. The urine showed albumin ++ , many red blood cells, and many casts. Hemolytic streptococci were cultured from the mastoid at operation and had been cultured from a draining ear 10 days before, during a clinic visit. The antistreptolysin titer reached 1000 units.

Course. The urinary findings cleared progressively over the next 3 weeks and were normal at the end of this time. Subsequently, in the clinic, over a period of 12 months, 8 urine examinations revealed normal findings, and the antistreptolysin titer had declined to 144 units. At the next visit, 3 months later, the boy reported fever for 2 days following swimming. He complained of general muscle stiffness. There had been some dysuria but no frequency or hematuria. Physical examination revealed no signs of nephritis. No throat culture was taken. The urine showed albumin ++++ and a normal sediment. The antistreptolysin titer was 200. Ten days later, a urine specimen was normal. The boy was next seen in the clinic approximately $11 / 2$ years later, reporting a severe head cold and cough, fever having reached $101^{\circ} \mathrm{F}$. over the preceding week. Hemolytic streptococci were cultured from the throat on two occasions and the antistreptolysin titer was 333 units. The urine showed only heavy albuminuria proven to be an orthostatic albuminuria on 5 examinations during the subsequent month. There were no clinical signs of nephritis.

\section{Case 6. J. L. (Hospital Number 410752)}

A boy of 4 with a $21 / 2$ weeks' history of pharyngitis, otitis media, and fever $102^{\circ} \mathrm{F}$., was admitted with acute nephritis. There was no edema, blood nonprotein nitrogen was $36 \mathrm{mgm}$. per $100 \mathrm{cc}$., and blood pressure was $95 / 55$. The urine showed gross hematuria, albumin ++++ , and many casts. Hemolytic streptococci were cultured from the throat, draining ears, and from the mastoid area at operation. The antistreptolysin titer rose to 1000 units.

Course. The urine cleared progressively, becoming completely normal in $2 \frac{1}{2}$ months. Ten months later, during which period urine examinations upon 6 occasions revealed no abnormality, the patient was read- mitted with acute mastoiditis. Temperature was $101^{\circ} \mathrm{F}$. There was no clinical evidence of nephritis. Hemolytic streptococci were cultured from the throat, ear, and from a postauricular abscess. The antistreptolysin titer reached 333 units. The urine showed a minimal albuminuria and a normal sediment daily during the 4 days that the patient was hospitalized. The urine 1 month later was normal. The patient was then lost to follow-up.

\section{Case 7. A.V. (Hospital Number 379219)}

A boy of 7 with a history of pharyngitis and cervical adenitis for 2 weeks was admitted with a peritonsillar abscess and acute nephritis with gross hematuria. There was slight edema of the extremities, blood pressure was $116 / 68$, blood nonprotein nitrogen $31 \mathrm{mgm}$. per $100 \mathrm{cc}$., serum albumin 3.9 per cent, and serum globulin 3.4 per cent. In addition to gross hematuria, the urine showed albumin ++++ , and casts. Hemolytic streptococci were cultured from the peritonsillar abscess, and the antistreptolysin titer reached 250 units.

Course. The urinary abnormalities subsided gradually, showing albumin + and occasional red blood cells at the end of 6 weeks. At the end of 5 months the urine was completely normal and the antistreptolysin titer revealed 83 units. Eighteen months after the date of healing, during which time urine examinations in the 1 st and 18th months revealed normal findings, the child was seen in the clinic with the complaint of cervical adenitis " off and on all winter," a recent exacerbation with fever having occurred one week previously. No clinical signs of nephritis were present. No throat culture was made, but the antistreptolysin titer was found to be 833 units. The urine at this time, one week after exacerbation of an infection with fever, revealed no changes. Unfortunately, the patient could not be followed.

\section{Case 8. R. M. (History Number 419533)}

A girl of 21 was admitted with pharyngitis and cervical adenitis. The urine was normal on admission and remained so during a period of 10 days of exacerbation and remission of the adenitis. Throat cultures revealed hemolytic streptococci and the antistreptolysin titer reached 555 units. Ten days later, the urine began to show ++++ albumin, a few casts, and red blood cells. There was no edema and no hypertension, but the blood urea rose to 0.79 gram per liter. The adenitis persisted and surgical drainage of a cervical abscess revealed, on culture, the presence of hemolytic streptococci. Blood cultures showed no growth. The urinary abnormalities gradually diminished and at the end of 6 weeks the urine was normal. Eight months after healing had occurred, during which period there had been 15 urine examinations, all normal, and the antistreptolysin titer had declined to 50 units, the patient was readmitted with pharyngitis and cervical adenitis of 12 hours' duration. Temperature was $101^{\circ} \mathrm{F}$. Throat culture showed a pure growth of hemolytic streptococci. The antistreptolysin 
titer rose to 333 units. Six days after admission, the patient developed mild erythema nodosum of the left foot and leg and right forearm. Eight days after admission, she developed a bronchopneumonia with sputum showing hemolytic streptococci and no pneumococci. Throughout this second admission, over a period of 1 month, there were 15 urine examinations all of which were normal. Fever was high, $101^{\circ}$ to $104^{\circ} \mathrm{F}$. over the first week of illness. There were no clinical signs of nephritis.

\section{GROUP II}

\section{Case 9. F. K. (Hospital Number 336058)}

A boy of 14 with a 2 weeks' history of pharyngitis was admitted with a peritonsillar abscess and acute nephritis with gross hematuria. Temperature was $104.6^{\circ}$ F., and blood pressure $134 / 64$. There was no edema. The urine, in addition to gross hematuria, showed albumin ++++ and many casts. Hemolytic streptococci were cultured from the incised peritonsillar abscess and the antistreptolysin titer reached 555 units. The patient left against advice after 3 weeks in the hospital, at which time the urine showed albumin ++ and rare red blood cells. Five days later, when seen in the clinic, the urine showed albumin ++ and 10 red blood cells per high power field. There was no history of intercurrent infection. When readmitted 1 week later, the urine was normal and remained so throughout his stay of 2 months. During this time, the antistreptolysin titer had declined to 200 . Throughout the next 6 months, 3 more urine examinations revealed normal findings. Ten months from the date of healing, the patient returned to the clinic, reporting a cold and cervical adenitis for 1 week, gross hematuria having appeared on the $2 d$ day. A urine examination in the clinic revealed albumin + , many red blood cells and no casts. There was no edema, and blood pressure was $130 / 95$. A throat culture at this time failed to show hemolytic streptococci. No determination of the antistreptolysin titer was made. Over the next 4 weeks, numerous red blood cells with albumin + and without casts were found in his urine on 3 examinations. One month later an examination revealed normal urine. During the next 3 years, there were 15 urine examinations revealing normal findings.

\section{Case 10. J. L. (Hospital Number 242232)}

A boy of 16 was admitted with Pneumococcus Type I lobar pneumonia of 3 days' duration. Urine on admission showed albumin + , occasional casts, and rare red blood cells. Blood pressure was 100/65. Three days later, his eyes became puffy, blood pressure 130/65, and the urine became smoky. Albumin ++++ was present. Blood urea rose to 1.6 grams per liter, and the phthalein excretion fell to 25 per cent. He was discharged 3 months later with urine still showing albumin ++ and many red blood cells. Subsequent follow-up in the clinic 1 month later showed albumin + and a few red blood cells per high power field and 1 year later albumin \pm with a normal sediment. During the next 10 years, he was followed in the clinic, the urine being negative on 8 occasions. At the end of this 10-year period the patient returned to the clinic with sore throat, dysphagia, cervical adenitis, and temperature $101^{\circ} \mathrm{F}$; blood pressure was $115 / 80$, and there was no edema. Urine showed albumin \pm and 35 red blood cells per high power field. A throat culture revealed no hemolytic streptococci but the antistreptolysin titer was found to be 333 units. During the next week, the patient's symptoms disappeared. The urine 1 year later, showed albumin \pm , sediment negative. The antistreptolysin titer was 333 units.

\section{SUMMARY}

The case histories of two groups of patients with healed acute nephritis are presented. The first group, offered in Table I, consists of 7 children and 1 adult. All of them had typical acute glomerulonephritis, associated at onset with an infection, bacteriologically and immunologically proved to be due to the hemolytic streptococcus. The duration of the nephritis in these patients varied from 3 to 9 months. There was a period of observation during the healed state ranging from 9 months to 3 years. All of the patients suffered subsequent infection, again bacteriologically or immunologically proved to be due to the hemolytic streptococcus. The antistreptolysin titers ranged from 333 to 1250 units. There were no clinical symptoms of nephritis associated with the second hemolytic streptococcal invasions in this group of patients. The urine showed no red blood cells and only an initial minimal and transient albuminuria associated with the febrile episodes. Thereafter, throughout periods of observation varying from 1 to 6 months in 7 of these patients, the urine showed no changes distinguishable from the normal. ${ }^{1}$ Unifortunately, in the remaining patient (Case $7, \mathrm{~A} . \mathrm{V}$.), only 1 urine was available for examination, 1 week after an attack of acute cervical adenitis. The findings at this time, however, were entirely normal.

One of the patients in this group (Case $5, \mathrm{~N}$. S.) was of particular interest. During his healed period, he developed fever with mild dysuria, without hematuria or frequency. A urine speci-

1 It should be said that one of us, J. D. L., has been able to find from time to time, with special technique, minimal amounts of albumin, occasional casts, and red blood cells in the urine of these patients, as he does with the same technique in the urine of normal children. 
men revealed albumin ++++ and occasional red blood cells. Ten days later, the urine was normal. One and a half years later, an examination, following a hemolytic streptococcal infection, showed that the boy had developed orthostatic albuminuria and was without evidence of nephritis. In the light of this, one is unable to state whether the single specimen showing heavy albuminuria $11 / 2$ years previously, associated with fever and dysuria, and followed later by one urine revealing normal findings, was of the orthostatic type or whether it represented nephritis. However, the second proved hemolytic streptococcal infection did not induce recurrence of the nephritis and $\mathbf{5}$ urine specimens observed over the next month continued to show only albuminuria of the orthostatic type.

The second group of patients consists of 2 adolescents presented in Table II. This group differs from Group I inasmuch as it consists of individuals healed of acute glomerulonephritis, who, on being subjected to subsequent infection, developed marked hematuria. In Case 9, F. K., aged 14, the original bout of nephritis followed an infection proved to be due to the hemolytic streptococcus; in the other, Case 10, J. L., aged 16, the nephritis followed Type I lobar pneumonia, and a concomitant infection with the hemolytic streptococcus was not known to be present. The nephritis lasted only 1 month in Case 9 but abnormal urinary findings persisted 15 months in Case 10. Each suffered subsequent infection. This was proved to be due to the hemolytic streptococcus in Case 10 and occurred 10 years after the healing of his nephritis. The ensuing infection in the other patient, Case 9, F. K., occurred 10 months after the healing of his nephritis and was presumably due to the hemolytic streptococcus but was not proved so. As has been stated above, the feature distinguishing these two patients from the individuals in Group I was the development of marked hematuria concomitant with subsequent hemolytic streptococcal infection and following a period in which they had been amply observed, as will be seen by the tables, to have been healed of their nephritis. The hematuria, although marked, was unaccompanied by significant albuminuria; it lasted 4 weeks in Case 9 and 1 week in Case 10. Subsequently, in Case 9, 15 urine examinations over the next 3 years revealed no abnormalities. Only 1 examination has been obtained in Case 10 and that 1 year after the disappearance of his hematuria. At this time, no urinary abnormalities were present.

In connection with these 2 patients exhibiting hematuria without significant albuminuria, it is of interest to point out that about 15 per cent of the patients with rheumatic fever at the Presbyterian Hospital show varying degrees of hematuria and slight albuminuria during their acute episodes whereas, at autopsy, only 3 of about 100 patients in Coburn's series (5) dying of active rheumatism showed any evidence of glomerulonephritis. It seems possible that the hematuria associated with the subsequent hemolytic streptococcal infection occurring in the two individuals in the second group of patients and unassociated with other signs, symptoms, or laboratory evidence of nephritis may be analogous to the renal manifestations occurring in many cases of rheumatic fever. However, it must be stated that the mechanism of the hematuria is unknown.

It is of interest immunologically that in acute nephritis, a disease the typical onset of which follows an infection with the hemolytic streptococcus, a second similar infection in these patients has not led to the chronic form of the disease. In the rheumatic state, however, a disease of proved association with the hemolytic streptococcus, recurrence of the disease, with or without apparent progressive damage, is common.

If the 10 cases presented may be assumed to be representative of the disease in general and if acute glomerulonephritis be a disease initiated by the hemolytic streptococcus, the permanence of recovery maintained in the face of subsequent hemolytic streptococcal invasion, as evidenced by the 10 patients under discussion, presents one aspect of immunity in hemolytic streptococcal disease.

The nature of this immunity is not known. Whether the defense mechanism results from the actual presence of immune bodies or whether it may result from histological and physiological changes within the kidney such as MacNider (3, 4) described occurring in his dogs with uranium nitrate nephritis, who were resistant to further damage by uranium nitrate, can only be a matter for conjecture at present. The important fact to be emphasized again in connection with this series 
of patients with healed acute nephritis is that, in spite of recurrent hemolytic streptococcal infection, and, in two instances, despite an accompanying recurrent hematuria, no one of these individuals has gone on to develop chronic progressive kidney disease.

The observations reported in this study receive amplification and support in the experience of Atchley and Loeb in the nephritic clinic at the Presbyterian Hospital over a period of 14 years and in the experience of one of us (J. D. L.) at the Babies Hospital over a 10 -year period. No case of healed acute glomerulonephritis has subsequently been observed to develop the chronic form of the disease. These cases, for the most part, were not studied from the bacteriological and immunological standpoint, but were presumably, in the majority of instances, secondary to infection with the hemolytic streptococcus.

\section{CONCLUSIONS}

1. A clinical, bacteriological, and immunological study with reference to hemolytic streptococcal infection has been made in 10 patients. These individuals were observed (1) during their acute glomerulonephritis, (2) throughout a subsequent healed period, and (3) during and following a subsequent infection with the hemolytic streptococcus.

2. Eight of the patients whose nephritis at onset was preceded by hemolytic streptococcal infection were observed through healed periods varying from 8 months to 3 years. Thereafter, in each instance, an intercurrent hemolytic streptococcal infection produced no recurrence of their nephritis.

3. Two of the patients with acute glomerulonephritis, preceded by hemolytic streptococcal infection in one and by Type I lobar pneumonia in the other, were observed through subsequent healed periods of 10 months and 10 years respectively. Each then underwent an infection proved to be caused by the hemolytic streptococcus in one instarice and presumably caused by that organism in the other. Both developed transient gross hematuria without significant albuminuria.

4. No one of the 10 patients studied has developed the chronic form of glomerulonephritis.

\section{BIBLIOGRAPHY}

1. Berglund, H., Medes, G., Huber, G. C., Longcope, W. T., and Richards, A. N., The Kidney in Health and Disease. Lea and Febiger, Philadelphia, 1935, p. 346.

2. Boyle, H. H., Aldrich, C. A., Frank, A., and Borowsky, S., The Addis count in children following clinical recovery from postinfectious nephritis. J. A. M. A., 1937, 108, 1496.

3. MacNider, W. deB., The development of the chronic nephritis induced in the dog by uranium nitrate. A functional and pathological study with observations on the formation of urine by the altered kidneys, J. Exper. Med., 1929, 49, 387.

4. MacNider, W. deB., The functional and pathological response of the kidney in dogs subjected to a second subcutaneous injection of uranium nitrate. J. Exper. Med., 1929, 49, 411.

5. Personal communication. 